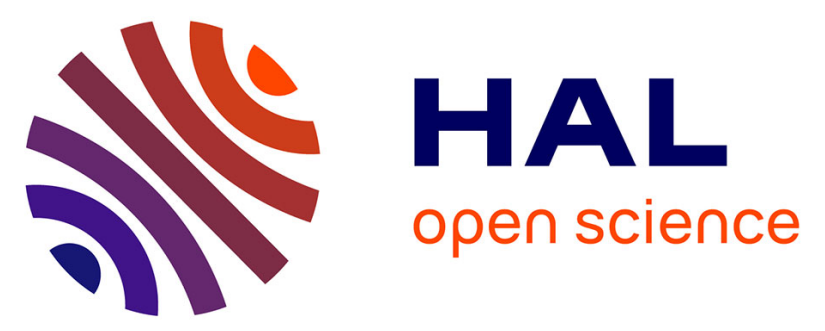

\title{
A 15 year prospective longitudinal study of disease progression in patients with HTLV-1 associated myelopathy in the UK.
}

Fabiola Martin, Alexandra Fedina, Silva Youshya, Graham P. Taylor

\section{- To cite this version:}

Fabiola Martin, Alexandra Fedina, Silva Youshya, Graham P. Taylor. A 15 year prospective longitudinal study of disease progression in patients with HTLV-1 associated myelopathy in the UK.. Journal of Neurology, Neurosurgery and Psychiatry, 2010, 81 (12), pp.1336. 10.1136/jnnp.2009.191239 . hal00559609

\section{HAL Id: hal-00559609 \\ https://hal.science/hal-00559609}

Submitted on 26 Jan 2011

HAL is a multi-disciplinary open access archive for the deposit and dissemination of scientific research documents, whether they are published or not. The documents may come from teaching and research institutions in France or abroad, or from public or private research centers.
L'archive ouverte pluridisciplinaire HAL, est destinée au dépôt et à la diffusion de documents scientifiques de niveau recherche, publiés ou non, émanant des établissements d'enseignement et de recherche français ou étrangers, des laboratoires publics ou privés. 


\section{A 15 year prospective longitudinal study of disease progression in patients with HTLV-1 associated myelopathy in the UK.}

Fabiola Martin ${ }^{1,2}$, Alexandra Fedina $^{1}$, Silva Youshya ${ }^{2}$, Graham P Taylor ${ }^{1,2}$

1. National Centre for Human Retrovirology, Imperial College Healthcare NHS Trust, St Mary's Hospital, London, UK

2. Section of Infectious Diseases, Faculty of Medicine, Imperial College, Norfolk Place, London, W2 1PG, UK

Corresponding author:

Dr Fabiola Martin

National Centre for Human Retrovirology

Imperial College Healthcare NHS Trust, St Mary's Hospital, London, W2 1NY

UK

f.martin@imperial.ac.uk

Tel: +44 2075943910

The Corresponding Author has the right to grant on behalf of all authors and does grant on behalf of all authors, an exclusive licence (or non exclusive for government employees) on a worldwide basis to the BMJ Publishing Group Ltd and its Licensees to permit this article (if accepted) to be published in the Journal of Neurology, Neurosurgery \& Psychiatry editions and any other BMJPGL products to exploit all subsidiary rights, as set out in our licence (http://innp .bmijournals.com/ifora/licence.pdf)." 


\section{Background}

HTLV-1 associated myelopathy (HAM) is a chronic non-remitting spastic paraparesis of insidious onset with lower limb weakness, spasticity and generalised hyperreflexia accompanied by bladder/bowel dysfunction and lower back pain in patients with positive HTLV-1 antibody. Cranial nerves and upper limbs are usually unaffected ${ }^{1-4}$. HTLV-1 infection is not a ubiquitous infection but endemic in the West Indies, Brazil, Japan, West Africa, Rumania and Iran ${ }^{5-16}$.

WHO diagnostic criteria of HAM defining three levels of ascertainment for HAM diagnosis: definite, probable and possible, excluding all conditions that could mimic $\mathrm{HAM}^{17}$, make geographically and genetically separate definite HAM cohorts comparable.

Studies of HAM prior to 1996 described progression during the first year followed by a plateau phase ${ }^{18-22}$. Recent studies, in both Japanese and AfroCaribbean cohorts, describe a more insidious onset with delayed diagnosis and continuous progression ${ }^{23,24}$. A more rapid onset and progression of HAM has been reported in patients transfused with HTLV-1 infected blood ${ }^{25}$ and in children ${ }^{26}$. Non- or slow progressing patients with HAM have not been defined so far, although patients with stable HAM have been described previously.

A Japanese study of 64 patients with HAM followed up for 10 years, showed deterioration of gait, muscle power and bladder function in $56 \%, 41 \%$ remained unchanged and $3 \%$ of the patients improved. The rate of disease progression was associated with higher HTLV-1 viral load and older age of onset (>65years) as well as a history of blood transfusion. This study did not 
provide details of the presenting symptom, presence or absence of pain or bladder/bowel symptoms, walking aid usage at baseline, time to progression to additional aid or the mortality rate ${ }^{23}$.

In 2006 a group in Martinique published longitudinal data on 123 AfroCaribbean patients with HAM. The mean time from onset to first clinic visit was 5.3 years whilst the duration of HAM at final follow up was 13 years. At last review $81.3 \%$ had started using at least one walking stick, $56.9 \%$ two walking sticks whilst $36.6 \%$ had become wheelchair dependent, with median times from onset of HAM to the use of these aids of 6, 13 and 21 years respectively. Wheelchair usage started after 25 years of disease if the age of onset was $<50$ years but after only 14 years if age at onset was $\geq 50$ years and this progression was significantly earlier in those patients with HTLV-1 viral load of $>10^{5} \mathrm{HTLV}-1$ DNA copies $/ 10^{6}$ PBMCs. Gender, history of blood transfusion and initial symptom (gait impairment $v$ urinary disturbance) did not affect the disease course. The authors concluded that motor disability worsens throughout the disease course and that faster early deterioration predicts the rate of progression in the long-term ${ }^{27}$. Of the 22 deaths $(17.8 \%)$, 19 (86\%) were attributed to HAM, with pneumonia and nephritis/sepsis as the dominant causes.

Two studies, from Brazil and Peru, have reported increased mortality in patients with rapid progression to immobility within two years of the onset of HAM ${ }^{28,29}$.

In the UK, a HTLV non-endemic country, an estimated 20000 persons are infected with HTLV-1 of which $3 \%$ will develop HTLV-1-associated myelopathy 30. The majority of diagnosed patients are managed at the National Centre for Human Retrovirology. 
The natural history of this unique cohort has not been described and may differ from other populations due to genetic, transmission and environmental factors. The aims of this prospective study were to describe the natural history and identify predictors of disease progression in this UK cohort of patients with HAM.

\section{METHODS}

\section{Subjects and methods}

For this observational natural history study, data were collected prospectively on all patients with HAM who attended the National Centre for Human Retrovirology (NCHR) in London from July 1993 to April 2007. Patients were followed up three monthly. Data were originally recorded in Excel and in addition all notes were hand searched for missing data. Patients were excluded if they were followed up for less than three months, had other confounding conditions or were co-infected with HIV. All comparisons are between the first and last clinic visits.

The descriptive variables were gender, ethnicity, perceived risk factor for HTLV-1 infection, first recalled symptom, age at onset, age at diagnosis of HTLV-1 infection or of HAM, duration of follow up and death. The clinical variables were use of walking aids, localisation and severity of pain, bladder and bowel function. Measurement of timed walk was initiated in 2001, as the seconds (sec) a patient takes to walk 10 meters (m) with or without walking aid. Patients were categorised as using no aid (AID0), one walking stick (AID1), two walking sticks (AID2), a frame (AID3) or being wheelchair (AID4) dependent. Pain was categorised by presence, localisation 
and severity, which was scored by the patient using a $10 \mathrm{~cm}$ long visual analogue scale. Bladder hyperactivity was recorded as urinary frequency and urgency whilst urinary retention as the need for catheterisation. Bowel function was recorded as normal, mild (>3/week), moderate ( $1-3 /$ week) and severe $(<$ 1/week) constipation. Data were collected on all symptomatic and potentially disease-modifying therapy given. Zidovudine and lamivudine were prescribed within a randomised controlled trial which is published ${ }^{31}$, and ciclosporin was prescribed within an ongoing clinical trial during data collection for this study. HTLV-1 viral loads, (HTLV-1 DNA copies/100 peripheral blood mononuclear cells [PBMCs]) quantified by 'in house' real-time PCR using the Roche LightCycler (Roche, Mannheim, Germany), were assayed prospectively ${ }^{32}$.

\section{Statistical Analysis}

Data were analysed in SPSS-14 through parametric (t-test) and nonparametric tests (Mann-Whitney Test and Wilcoxon Signed Ranks Test) for continuous variables and chi-square (Pearson Chi-Square Test/ Fisher's Exact test) for categorical variables. The categorical variables were gender, ethnicity, perceived risk factor for HTLV-1 infection, first recalled symptom, use of walking aids, localisation of pain, bladder and bowel function and death. The continuous variables were age at onset, age at diagnosis of HTLV1 infection or of HAM, duration of disease and follow up, timed walk, pain score and HTLV-1 viral load. Kaplan Mayer survival analysis was used for survival data. For the prediction of AID change a logistic regression model was applied, using the following explanatory variables: age of onset, risk factors for HTLV-1 acquisition, HTLV-1 VL, rate of change timed walk, timed walk, absence/presence of pain and pain score at first visit. For the prediction 
of the deterioration of timed walk an univariate general linear regression model was used, analysing the effects of the following covariates: age of onset, HTLV-1 VL, timed walk and pain score at first visit and fixed factors: gender, ethnicity, risk factor for HTLV-1 infection and absence/presence of pain. Forward and backward Wald was used for the best-fit model. Cox regression was used to create a predictive model for time-to-event data. Results were assumed statistically significant and the null hypothesis was rejected if a $p$ value $<0.05$ was achieved.

\section{Results}

Of the 55 patients with HAM, 48 were included in the analysis. Seven patients were excluded, five because of insufficient data, one patient had polymyositis and one HIV-1 co-infection.

Table 1 gives an overview on demographics, patients age of onset and follow up as well a summary of disease modifying and palliative medication prescribed at first visit. Patients were mostly female, of Afro-Caribbean origin, and reported mother-to-child transmission and/or unprotected sexual intercourse with a person from an endemic region as the most likely route of HTLV-1 acquisition. Four patients (8.3\%) cited blood transfusion before 2002, when obligatory screening for HTLV-1/2 antibodies was implemented in the UK, as their sole risk.

The most common first symptom was unilateral leg weakness at a median age of 48 years. Five (10.4\%) patients were diagnosed with HTLV-1 infection prior to developing HAM, one of whom developed HAM during follow up. In this sub-group the median time from diagnosis of HTLV-1 infection to onset of disease was 1.2 years. Median follow up was 3.8 years resulting in 212 
person-years (py) of follow up. Oral prednisolone, zidovudine, lamivudine, methotrexate and ciclosporin were prescribed as disease modifying drugs during follow up.

\section{Time to first use of a walking aid}

At the baseline visit 38 (79\%) patients were walking compared to $32(68 \%)$ patients at last clinic visit $(p=0.25)$. At baseline $13(27 \%)$ patients were walking unaided (AID0), 25 (52\%) were using walking aids (AID1, 2 and 3), eight (17\%) were wheelchair dependent (AID4) and two (4\%) were bed bound. During follow up 19 (54\%) patients needed additional aid: seven patients progressed to AID1, three to AID2, three to AID3 and six to AID4. The median times from onset of HAM to AID1, AID 2, AID 3 and AID4 were 11 (range $0.8-24.5,95 \% \mathrm{Cl} 2.8-17.30[\mathrm{Cl}]$ ), 11.2 (range $6.4-16.5,95 \% \mathrm{Cl} 1.2-$ 16), 11.3 (range 6.9-14, 95\% Cl 8.3-14) and 18 years (range 14-22.1, 95\% Cl 14-22).

At last visit the mobility of two patients (4\%) had improved: one could transfer from bed to wheelchair and one needed one walking stick instead of two.

\section{Progression in timed walks}

Comparing baseline with last visit, mean timed walk deteriorated in 29 (81\%) by $+4.25 \mathrm{sec} / 10 \mathrm{~m} /$ year $(-0.13$ to 24.6 , median 1.27$)$ including four patients who became wheelchair bound with median deterioration rate of +17.1 $\mathrm{sec} / 10 \mathrm{~m} / \mathrm{y}(+5.9$ to +24.6$)$. In seven patients $(19 \%)$ timed walk improved by $-35.5 \mathrm{sec} / 10 \mathrm{~m} / \mathrm{y}(-160$ to -2.6 , median -7.7$)$ however these patients were followed up for only a median of 0.4 years $(0.25-0.92)$ and the rate of improvement in timed walk has been assumed to continue at the same rate 
for the whole year and is therefore an overestimate. Timed walks deteriorated even in patients who walked without any need for further aid by a median of $+1.98 \mathrm{sec} / 10 \mathrm{~m} /$ year.

Four (11\%) patients were categorised as long term non-progressors: their median timed walk rate changed by only $+0.2 \mathrm{sec} / 10 \mathrm{~m} / \mathrm{y}(-0.13$ to +0.67$)$ without needing any additional aid during a median follow up 4.3 years (2.76.8). Two (6\%) patients were slow-progressors: they needed one walking stick after a median of 11.5 years (9.7-13.2) disease duration and their median timed walk deteriorated by only $+0.3 \mathrm{sec} / 10 \mathrm{~m} / \mathrm{y}(+0.24$ to +0.33$)$ during a median follow up of 6.3 years $(5.3-7.3$, ). Three (6\%) patients progressed rapidly and became wheelchair or bed-bound in less than two years from onset, one of whom died at the age of 40 years. Timed walk, rate of progression and HTLV-1 VL were analysed by age of onset as presented in other publications ${ }^{23,33}$. Patients with a younger age of onset ( $\leq 50$ years) were more likely to use walking aids $(p=0.005)$ and suffer from pain $(p=0.03)$ at baseline compared to older onset group.

Four patients cited blood transfusion as their only risk for HTLV-1 acquisition of which three patients recalled first symptoms at a young age $(\leq 50 \mathrm{y}$. Although none of the patients progressed rapidly or died during follow up, two patients needed more aid (a frame and a wheelchair) and the median rate of progression of timed walk was faster in these $(+4.9 \mathrm{sec} / 10 \mathrm{~m} / \mathrm{y}$ [0.5-13.3], $95 \% \mathrm{Cl}-9.8-+22)$ compared to non-transfused patients $(+1.2 \mathrm{sec} / 10 \mathrm{~m} / \mathrm{y}$ [0.01-6.6], $95 \% \mathrm{Cl}+1.1-+3, \mathrm{p} 0.02)$. 


\section{Pain}

Twenty-seven (63\%) patients reported pain at first visit and $23(53 \%)$ at last review $(p=0.3)$. At both time points more patients had permanent compared to intermittent pain (first: 11 [69\%] v 5 [31\%], last: 13 [81\%] v 3 [19\%]). Low back pain alone was reported in 14 (52\%), low back and leg pain in $7(26 \%)$ and leg pain alone in 5 (19\%). At last visit 8 (30\%) patients had become pain free but $4(25 \%)$ previously pain free patients reported pain.

The median pain score of the whole group did not differ significantly between first, $6 \mathrm{~cm}(2-10,95 \% \mathrm{Cl}: 4.9-7.1)$ and last visit, $5.5 \mathrm{~cm}(1.5-10,95 \% \mathrm{Cl}: 5.2-$ 7.6, $p=0.2)$. This however masks the considerable individual changes. In 10 patients the pain score worsened significantly from a median of $2.5 \mathrm{~cm}(0-8$, $95 \% \mathrm{Cl}: 0.8-5.2)$ at first visit to $8 \mathrm{~cm}(4-10,95 \% \mathrm{Cl}: 5.7-8.8, \mathrm{p}=0.05)$ at last visit. In 15 patients pain improved significantly between the two time points (first: 7cm [2-10], 95\%Cl: 5-8; last: 0cm [0-9.5], 95\% Cl: 0.8-4.4).

\section{Bladder and Bowel function}

Although there was no significant difference in the number of patients complaining of bladder problems at the two time points (first: $37 / 41$ [90\%] v last 35/41 [85\%], $p=0.5)$, significantly more patients were catheterising at last $20(49 \%)$ compared to first visit $11(27 \%) p=0.04$

Most patients suffered from bladder hyperactivity (32 [86\%]) and urinary retention was observed in five [14\%]. Obstructive nephropathy was present at baseline in one patient and developed during follow up in a second.

Twenty-five (63\%) were constipated at first and $24(60 \%)$ at last visit. This apparent lack of change masks considerable individual variation. In seven 
(18\%) patients constipation worsened between first and last visit, whilst in ten (25\%) it improved of whom seven (18\%) became asymptomatic.

\section{Mortality}

During follow up five (10.6\%) patients died giving a mortality rate of 2.4/100 py. Three patients were male and the median age at time of death was 57 years (36-78). Four deaths were directly associated with HTLV-1 infection: one patient developed adult T-cell leukaemia/lymphoma, one pneumonia with respiratory failure and two had severe HAM with disseminated inflammation. Cause of death of one patient was unknown. Death occurred at a median of 9.7 years from onset (2.42-20.3) and 4.4 years of follow up (1.34-10.7) (Figure 1).

\section{HTLV-1 viral load}

The HTLV-1 viral load (VL) of the cohort remained essentially unchanged over time (first: median 14 [0.002-140], 95\% Cl: 13-28 v last: median 13 [0.01-70], $95 \% \mathrm{Cl}: 13.3-24, \mathrm{p}=0.6$, Figure 2). The median $\mathrm{VL}$ of the asymptomatic patient who developed HAM was high at baseline (9.8 [1.6-22.5] copies/ 100 PBMCs) and remained unchanged over time.

HTLV-1 VL was neither associated with a change in aid usage $(p=0.8)$ nor with pain at baseline $(p=0.7)$. Timed walk deterioration rate was not significantly associated with HTLV-1 VL at baseline $(p=0.2)$. However median HTLV-1 VL were higher in patients who were younger at onset and whose need for aid and timed walk increased over time ( $\leq 50 \mathrm{y}: 11.2$ [0.002-70], 95\% Cl 5.7 -38; > 50y: 1.7 [1.2-2.4], 95\% 0.8-2.7, $p=0.09)$. 


\section{Prediction of deterioration of gait}

In a logistic regression analysis investigating the association of an increase in AID usage with the in the methods section mentioned variables identified the rate of progression of timed walk/year $(p=0.05,95 \% \mathrm{Cl} 1-1.3)$ as the only significant parameter which predicted $69 \%$ of progression in aid correctly. A relationship between the rate of timed walk change/ year and the in the methods section listed baseline measurements could not be established in a univariate general linear model.

\section{Discussion}

On the basis of ethnicity our cohort data should be most comparable with data from the Caribbean and from Brazil ${ }^{34,35}$. Similarities are the female predominance, route of HTLV-1 acquisition, onset before the age of 50 , gait impairment as the most common first symptom and slow but continuous progression of disability as well as a high but stable HTLV-1 VL over time. On average patients are diagnosed earlier after the onset of HAM in the UK (mean 3.8, median 2 years) than in Martinique (mean 5.3, median 3 years). This might be due to patients' ability and/or choice to access healthcare earlier. In the UK patients could walk unaided for longer (10 v 6 y) and needed a wheelchair later (18 v 21y) than patients in Martinique. The difference in the time to first use of a walking aid could be due to an earlier diagnosis of HAM and/or more intense physiotherapy and symptomatic treatment of pain and spasticity in the UK.

Patients who were younger at onset had a higher baseline HTLV-1 VL and progressed more rapidly as assessed by use of walking aids and timed walk. 
In addition the few patients whose risk for acquiring HTLV-1 infection was blood transfusion were also more likely to progress in their need for aid. The rate of deterioration of timed walk seemed to be weakly associated with higher HTLV-1 viral load at first visit irrespective of an increase of aid usage in our cohort. These associations might be more significant in a larger cohort. Timed walk rate is most meaningful for those patients who are not using any aid and are followed up for more than one year. We describe for the first time the expected rate of deterioration in walking speed of $2 \mathrm{sec} / 10 \mathrm{~m} / \mathrm{y}$ in patients with HAM who do not require any change in walking aid. Thus according to current disability scales only $54 \%$ of our initially ambulant patients would have had a documented deterioration whereas using timed walk a further $20 \%$ of patients were seen to deteriorate during follow up. Our data, demonstrating improvement in timed walk in patients who have only been attending the clinic for between 3 and 12 months, whilst suggesting that symptomatic management and physical therapy can have a significant impact on mobility in the short-term, should also caution that this may mask continuing progression of the underlying pathology. For the first time we are describing patients with HAM whose rate of timed walk changed only $\leq 1 \mathrm{sec} / 10 \mathrm{~m} / \mathrm{y}$ from baseline during a follow up time of $\geq 2$ years as non-progressors if they did not need any walking aid and as slow-progressors if they needed only one additional aid. These definitions will help to compare HAM subgroups with those who progress continuously or rapidly. Furthermore we have seen that the rate of deterioration in timed walk in patients who subsequently became wheelchair dependent was much faster, suggesting that timed walks identify those patients most at need of therapeutic intervention. 
HTLV-1 infection was associated with a 1.3 fold increased risk of death from all causes excluding ATLL in Japan ${ }^{36}$. The relative mortality rate was 1.7 for HTLV-1 infected compared to uninfected subjects in Guinea -Bissau and was mortality associated with higher HTLV-1 viral loads but neither the cause of death nor the prevalence of ATLL are given ${ }^{37} .25 \%$ of 123 patients with HAM from Martinique died within 20 years of disease onset ${ }^{38}$. A report from the UK's Health Protection Agency documented a higher mortality rate associated with HTLV-1 infection in the UK in patients of Afro-Caribbean ethnicity and in those living far from centres looking after HTLV-1 positive patients ${ }^{39}$. In our population $10.6 \%$ of the patients with HAM died within a mean of 9.7 years from the onset of HAM. The mortality rate in our cohort was $2.4 / 100$ py follow up compared to an age-adjusted mortality rate of $1 / 100$ py in general UK population. Therefore a higher rate of all cause non-neoplastic mortality is associated with HAM in the UK. Deaths in our cohort were more common in younger, more disabled patients and appeared to be more directly related to HTLV-1 infection, whereas in Martinique deaths were mostly commonly due to complications of debilitating neurological disease.

We also present prospectively collected longitudinal data on HTLV-1 VL of patients with HAM. Neither the mean nor the median HTLV-1 viral load changed significantly over time and more importantly the patient who developed HAM during follow up had a high set point of HTLV-1 VL prior to onset of symptoms which fluctuated only insignificantly over time. However we do not have enough data to prove that a significantly higher VL always precedes the development of HAM although this is commonly assumed. This study has the many limitations of a cohort study of a rare disease: small numbers, variable follow up in some cases $<1$ year, no comparator arm and 
not controlled for treatment. The underlying deterioration of HAM resulting in a steady deterioration may obscure fluctuating improvements in patients followed up for longer as only the final outcome is documented. Therefore a potential transient improvement or stalling of the disease process might have been missed. However, careful description of a cohort essentially managed with only symptomatic therapies provides a rate of change in timed walk against which novel interventions can be judged. In conclusion, a 10m timed walk, which is simple and accessible, provides a rapid and valuable additional clinical measure in patients with HAM, demonstrating the continuous progressive nature of this condition and a tool to identify patients who might most benefit from more targeted management

Funding: None.

Competing interests: None. 


\section{Reference List}

1. Cruickshank, J. K. et al. Tropical spastic paraparesis and human T cell lymphotropic virus type 1 in the United Kingdom. Brain 112 ( Pt 4), 10571090 (1989).

2. Orland, J. R. et al. Prevalence and clinical features of HTLV neurologic disease in the HTLV Outcomes Study. Neurology 61, 1588-1594 (2003).

3. Franzoi, A. C. \& Araujo, A. Q. Disability profile of patients with HTLV-Iassociated myelopathy/tropical spastic paraparesis using the Functional Independence Measure (FIM). Spinal Cord. 43, 236-240 (2005).

4. Olindo, S. et al. Natural history of human T-lymphotropic virus 1-associated myelopathy: a 14-year follow-up study. Arch Neurol 63, 1560-1566 (2006).

5. Lee, H., Anderson, E., Allain, J. P. \& Gonzaga, A. HTLV-1 infection in Brazil. Blood 73, 1742 (1989).

6. Moreira, E. D., Jr. et al. Seroepidemiology of human T-cell lymphotropic virus type I/II in northeastern Brazil. J. Acquir. Immune. Defic. Syndr. 6, 959963 (1993).

7. dos Santos, J. I. et al. Seroprevalence of HIV, HTLV-I/II and other perinatally-transmitted pathogens in Salvador, Bahia. Rev. Inst. Med. Trop. Sao Paulo 37, 343-348 (1995).

8. Sanders, R. C. et al. The prevalence of antibodies to human T-lymphotropic virus type I in different population groups in Papua New Guinea. Arch. Virol. 130, 327-334 (1993).

9. Safai, B. et al. Prevalence of HTLV type I infection in Iran: a serological and genetic study. AIDS Res. Hum. Retroviruses 12, 1185-1190 (1996).

10. Abbaszadegan, M. R. et al. Prevalence of human T-lymphotropic virus type 1 among blood donors from Mashhad, Iran. J. Clin. Microbiol. 41, 2593-2595 (2003).

11. Necula A. Screening for Anti-HTLV in Romania- 1999 to 2005- Update. 195-2005.

Ref Type: Unpublished Work

12. Gastaldello, R., Hall, W. W. \& Gallego, S. Seroepidemiology of HTLV-I/II in Argentina: an overview. J. Acquir. Immune. Defic. Syndr. 35, 301-308 (2004).

13. Sarkodie, F. et al. Screening for viral markers in volunteer and replacement blood donors in West Africa. Vox Sang. 80, 142-147 (2001). 
14. Murphy, E. L. et al. Human T-lymphotropic virus type I (HTLV-I) seroprevalence in Jamaica. I. Demographic determinants. Am. J. Epidemiol. 133, 1114-1124 (1991).

15. Mueller, N., Okayama, A., Stuver, S. \& Tachibana, N. Findings from the Miyazaki Cohort Study. J. Acquir. Immune. Defic. Syndr. Hum. Retrovirol. 13 Suppl 1, S2-S7 (1996).

16. Yamaguchi, K. Human T-lymphotropic virus type I in Japan. Lancet 343, 213216 (1994).

17. Castro-Costa, C. M. D. et al. Proposal for Diagnostic Criteria of Tropical Spastic Paraparesis/HTLV-I-Associated Myelopathy (TSP/HAM). AIDS Research and Human Retroviruses 22, 931-935 (2006).

18. Araujo, A. Q., Leite, A. C., Dultra, S. V. \& ndrada-Serpa, M. J. Progression of neurological disability in HTLV-I-associated myelopathy/tropical spastic paraparesis (HAM/TSP). J Neurol Sci. 129, 147-151 (1995).

19. Roman, G. C. \& Roman, L. N. Tropical spastic paraparesis. A clinical study of 50 patients from Tumaco (Colombia) and review of the worldwide features of the syndrome. J Neurol Sci. 87, 121-138 (1988).

20. Vernant, J. C. et al. Endemic tropical spastic paraparesis associated with human T-lymphotropic virus type I: a clinical and seroepidemiological study of 25 cases. Ann Neurol 21, 123-130 (1987).

21. Montgomery RD \& Cruickshank EK, R. W. M. W. Clinical and pathological observations on Jamaican neuropathy: a report on 206 cases. Brain 87, 425462 (1964).

22. Cruickshank, J. K. et al. Tropical spastic paraparesis and human T cell lymphotropic virus type 1 in the United Kingdom. Brain 112 ( Pt 4), 10571090 (1989).

23. Matsuzaki, T. et al. HTLV-I proviral load correlates with progression of motor disability in HAM/TSP: analysis of $239 \mathrm{HAM} / \mathrm{TSP}$ patients including 64 patients followed up for 10 years. J Neurovirol 7, 228-234 (2001).

24. Olindo, S. et al. Natural history of human T-lymphotropic virus 1-associated myelopathy: a 14-year follow-up study. Arch Neurol 63, 1560-1566 (2006).

25. Nakagawa, M. et al. HTLV-I-associated myelopathy: analysis of 213 patients based on clinical features and laboratory findings. J Neurovirol. 1, 50-61 (1995).

26. Bittencourt, A. L., Primo, J. \& Oliveira, M. F. Manifestations of the human Tcell lymphotropic virus type I infection in childhood and adolescence. $J$ Pediatr. (Rio J) 82, 411-420 (2006).

27. Olindo, S. et al. Natural history of human T-lymphotropic virus 1-associated myelopathy: a 14-year follow-up study. Arch Neurol 63, 1560-1566 (2006). 
28. Lima, M. A., Harab, R. C., Schor, D., ndrada-Serpa, M. J. \& Araujo, A. Q. Subacute progression of human T-lymphotropic virus type I-associated myelopathy/tropical spastic paraparesis. J Neurovirol. 13, 468-473 (2007).

29. Gotuzzo, E. et al. Clinical characteristics of patients in Peru with human T cell lymphotropic virus type 1-associated tropical spastic paraparesis. Clin Infect. Dis 39, 939-944 (2004).

30. Tosswill, J. H. C., Taylor, G. P., Tedder, R. S. \& Mortimer, P. P. HTLV-Iassociated disease in England and Wales 1993-7:A retrospective study of serology requests. BMJ 320, 611-612 (1999).

31. Taylor, G. P. et al. Zidovudine plus lamivudine in Human T-Lymphotropic Virus type-I-associated myelopathy: a randomised trial. Retrovirology. 3, 63 (2006).

32. Goon, P. et al. HTLV-I specific CD4+ T cells: Immunodominance hierarchy and preferential infection with HTLV-I. J Immunol 172, 1735-1743 (2004).

33. Olindo, S. et al. Natural history of human T-lymphotropic virus 1-associated myelopathy: a 14-year follow-up study. Arch Neurol 63, 1560-1566 (2006).

34. Araujo, A. Q., Leite, A. C., Dultra, S. V. \& ndrada-Serpa, M. J. Progression of neurological disability in HTLV-I-associated myelopathy/tropical spastic paraparesis (HAM/TSP). J Neurol Sci. 129, 147-151 (1995).

35. Olindo, S. et al. Natural history of human T-lymphotropic virus 1-associated myelopathy: a 14-year follow-up study. Arch Neurol 63, 1560-1566 (2006).

36. Arisawa, K. et al. Human T-lymphotropic virus type-I infection, survival and cancer risk in southwestern Japan: a prospective cohort study. Cancer Causes Control 14, 889-896 (2003).

37. Holmgren, B. et al. Mortality associated with HIV-1, HIV-2, and HTLV-I single and dual infections in a middle-aged and older population in GuineaBissau. Retrovirology. 4, 85 (2007).

38. Olindo, S. et al. Natural history of human T-lymphotropic virus 1-associated myelopathy: a 14-year follow-up study. Arch Neurol 63, 1560-1566 (2006).

39. Tsui, B. et al. Mortality among individuals less than 60 years diagnosed with HTLV-I in England and Wales: 1993-2003. 4-5-2005.

Ref Type: Unpublished Work 
Table 1: Demographics, follow up and treatment of 48 patients with HAM.

\begin{tabular}{|c|c|}
\hline Gender & Number (\%) \\
\hline Female & $38(79.2)$ \\
\hline \multicolumn{2}{|l|}{ Ethnicity } \\
\hline $\begin{array}{r}\text { Afro-Caribbean } \\
\text { Caucasian } \\
\text { Other ethnic background }\end{array}$ & $\begin{array}{l}38(79.2) \\
6(12.5) \\
4(8.3)\end{array}$ \\
\hline \multicolumn{2}{|l|}{ Attributed risk factor(s) for HTLV-1 infection } \\
\hline $\begin{array}{r}\text { Sexual intercourse alone } \\
\text { Breast-fed + sexual intercourse } \\
\text { Blood product recipient before } 2002 \\
\text { Breast-fed + sexual intercourse }+ \text { blood product recipient }\end{array}$ & $\begin{aligned} 3 & (6.3) \\
40 & (83.3) \\
4 & (8.3) \\
1 & (2.1)\end{aligned}$ \\
\hline & $\begin{array}{l}\text { Median (range), } \\
95 \% \mathrm{Cl}\end{array}$ \\
\hline $\begin{array}{l}\text { Age at time of first recalled symptom (years) } \\
\text { Age at time of diagnosis (years) }\end{array}$ & $\begin{array}{l}48 \text { (10-72), } 42.5-50 \\
51 \text { (26-73), } 46-55\end{array}$ \\
\hline $\begin{array}{l}\text { Time between onset and diagnosis (years) } \\
\text { Duration of follow up (years) } \\
\text { Duration of symptoms (onset - last follow up in years) }\end{array}$ & $\begin{array}{c}2(1-19), 2.2-5.5 \\
3.8(0.5-13), 2.9-5 \\
11.6(1.2-31), 10.6-15\end{array}$ \\
\hline & Number (\%) \\
\hline Treatment for HAM at $1^{\text {st }}$ visit & $46(95.8 \%)$ \\
\hline $\begin{array}{r}\text { Oral prednisolone } \\
\text { Antiretrovirals } \\
\text { Methotrexate } \\
\text { Ciclosporin }\end{array}$ & $\begin{array}{l}1(2.1 \%) \\
1(2.1 \%) \\
0 \\
0\end{array}$ \\
\hline Treatment for spasticity at $1^{\text {st }}$ visit & $42(87.5 \%)$ \\
\hline Baclofen & $13(27.1 \%)$ \\
\hline Treatment for urinary frequency, at $1^{\text {st }}$ visit & $42(87.5 \%)$ \\
\hline Oxybutinin & $12(25 \%)$ \\
\hline Treatment for constipation at 1st visit & $40(83.3 \%)$ \\
\hline $\begin{array}{r}\text { Fibre } \\
\text { Laxative } \\
\text { Enema }\end{array}$ & $\begin{array}{c}14(29.2 \%) \\
11(22.9 \%) \\
1(2.1 \%\end{array}$ \\
\hline
\end{tabular}


Figure 1: Kaplan Maier survival analysis of all patients from onset of disease to last follow up or death. Censored = patient reaching their last follow up.

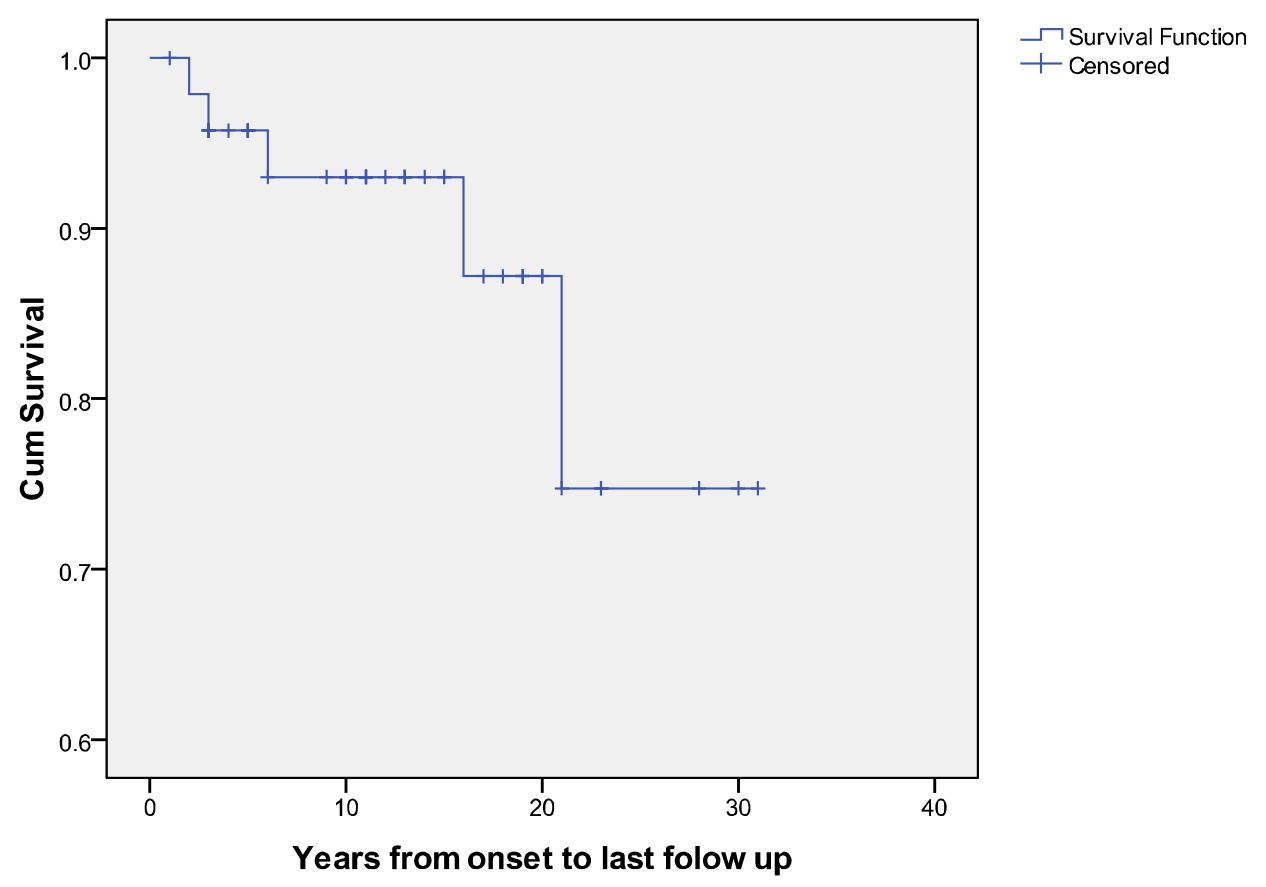


Figure 2: Mean HTLV-1 viral load (log copies/ 100 PBMCs) of all patients by year of follow up. SD= standard deviation, $\mathrm{PBMCs}=$ peripheral blood mononuclear cells

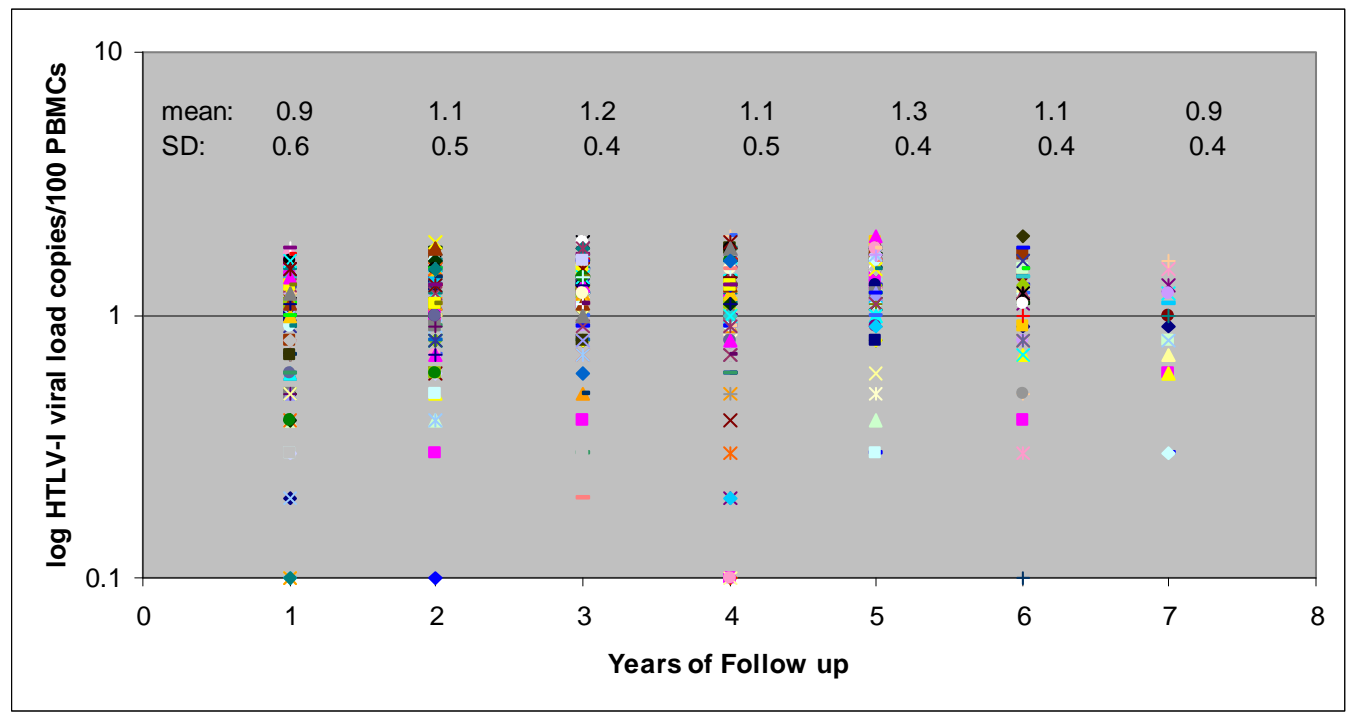

